Research Article

\title{
Using Design and Graphic Design with Color Research in AI Visual Media to Convey
}

\author{
Chunyan Liu $\mathbb{D}^{1}{ }^{1}$ Zhe Ren, ${ }^{2}$ and Sen Liu $^{3}$ \\ ${ }^{1}$ School of Arts, Tianjin University of Commerce, Tianjin, 300134 Tianjin, China \\ ${ }^{2}$ College Arts and Sciences, Dakota State University, $820 \mathrm{~N}$ Washington Ave Madison, SD 57042, USA \\ ${ }^{3}$ Graduate School, Jingdezhen Ceramic Institute, Jingdezhen, 333000 Jiangxi, China
}

Correspondence should be addressed to Chunyan Liu; logitech229@tjcu.edu.cn

Received 2 July 2021; Revised 16 August 2021; Accepted 26 August 2021; Published 16 September 2021

Academic Editor: Haibin Lv

Copyright (c) 2021 Chunyan Liu et al. This is an open access article distributed under the Creative Commons Attribution License, which permits unrestricted use, distribution, and reproduction in any medium, provided the original work is properly cited.

With the development of science and technology and social progress, people can reveal design information in different forms on a daily basis. The more common visual design information, the more important its development status. In visual communication design, the two most important factors are color and image. These two factors can play a great role and can attract the public's attention. This article is based on AI technology to study the design of color matching and image application in visual media communication design, aiming to innovate the method of visual media communication design, breaking through the traditional color matching and image application, so as to better use color art in visual communication design and graphic art and design excellent works. First, this article elaborates on the concept, main components, and influencing factors of visual communication design and also introduces the application of AI technology, then designs a visual media communication design model based on AI technology, and finally analyzes the current status of visual media communication design, usage, and satisfaction. From the analytical analysis, it appears that the optical media interface is commonly used for packaging design, responding to $45.6 \%$; it is used more in the film and television media industry, reaching $68 \%$; $49 \%$ of the public are very satisfied with AI visual media communication design. The above data fully shows that the application of AI visual media communication design is very wide, and the color matching and image use are very prominent, and the public is willing to accept AI visual media communication design works.

\section{Introduction}

We live in a colorful world; colors and images have a great impact on our vision, so the design of visual communication cannot be achieved without colors and images. Color, graphics, and text are the three main elements in a visual media design. We will not overlook the important role of color in the process of designing optical media. The purpose of visual communication design is to attract more people, make their products more visual and creative, so as to realize the value of goods. The application of AI technology in the multimedia field is not long, but it has made great progress, such as multimedia players and intelligent voice speakers. Similarly, artificial intelligence technology can be applied to the design of visual media communication and use a more visual style for its color and images, as well as a better artistic result.
Graphic design elements are widely used in different fields of design, such as cross-media platform dynamic design. These elements are used more and more, adapting to the development trend of the times and the popular aesthetic intentions. The three elements can show colorful visual effects in a static form, bringing sensual enjoyment and psychological resonance to the public. Extended sketches have different dots, lines, and levels of different shapes, while color is a useful function to increase the contrast with the appearance of the sketch, as well as the text to show the details of the photos correctly and directly.

The transformation of Huang et al.'s socio-economic structure to an $\mathrm{M}$ shape gave rise to a new consumer concept: affordable fashion. Thanks to the high popularity of Internet access and handheld mobile devices, it has become a norm for modern consumers to browse and shop clothing 
products or information quickly and conveniently. Use simulated web pages and questionnaires to conduct formal experiments, analyze product photos that combine three visual codes (product, character, and environment), and check which of them can stimulate psychological simulations. However, he still uses traditional visual communication methods without any innovation [1]. Shi and Zhang visual communication design is part of communication science. However, the symbols in visual communication design are difficult to express in words. Therefore, the audience is not easy to accept and understand. Therefore, designers introduce communication theory into visual communication design and establish an effective visual communication design communication model framework theory. This mode can effectively realize the transmission of information and provide a new theory for the research of visual communication design. However, his research theory did not fundamentally promote the development and innovation of visual communication design [2, 3]. Mamoshina et al. outline the next generation of artificial intelligence and blockchain technology and propose innovative solutions that can be used to accelerate biomedical research and enable patients to use new tools to control and profit from their personal data and provide incentives for continued health monitor. They introduced new concepts to evaluate and evaluate personal records, including data combinations, time, and relationship values. However, the accuracy of their research data has yet to be confirmed [4].

The innovations of this article are (1) the combination of qualitative research and quantitative research is fully demonstrated in the fourth part of this article; (2) the combination of theoretical research and empirical research, based on the analysis of AI technology theory, analyzes the visual media communication design.

\section{Design Research Methods of Color Matching and Image Application in AI Visual Media Communication Design}

2.1. Brief Description of AI Visual Media Communication Design. Visual communication refers to the design of information transmission using visual symbols. With the advancement of science, not only printing art, but also various technologies such as graphics, electronics, and multimedia design have been rapidly developed. The design of visual communication is to "transmit" the information conveyed to the audience, and it also needs the audience's acceptance [5]. The purpose of communication design should be to make the other party understand. The so-called "visual symbols," as the name suggests, refers to photos, televisions, movies, etc., various design products, urban architecture, various sciences and texts, etc., which can express people with specific characteristics. This includes 4 procedures, who is, to whom, to whom, and what information to communicate $[6,7]$.

The key elements of color design in visual media communication are (1) color design and images. In the design of visual media communication, the relationship between color and image is closely linked. The design and color of the design not only reflects the existence of the object and the object but also must be creative and beautiful [8-10]. (2) Color design and text. Text and color are interdependent. The text has a certain color, whether it is religious or other political color. Therefore, the symbolic meaning of color must be considered in the color design of the text [11]. (3) Color design and material media. The completion of the color scheme must be demonstrated by a number of factors. Thus, as time goes on, the system increases, and the color spectrum increases significantly [12]. (4) Color design and application materials. Color quality is largely reflected in the selection of applied materials, which directly reflects its texture. Therefore, color design is inseparable from materials such as pigments, dyes, and inks $[13,14]$.

The influencing factors of color matching in visual media communication design include the following: (1) color design, including design methods and media, design goals, design objects, and design concepts; (2) economic and cultural influence. It mainly affects the content conveyed by visual media, including the influence on various periods and various religious environments; and (3) market strategic positioning of design objects. Color design must fully consider the personality of the audience, meet the aesthetic requirements of each social class, and meet the audience's consumer psychology and spiritual and cultural pursuits $[15,16]$. From this, we can see the importance of color matching in the design of visual media communication. The workflow of the visual media communication system is shown in Figure 1.

In the era of digital media, the characteristics of visual communication design have also undergone great changes. In order to further strengthen its implementation, its characteristics must be analyzed. First of all, from the perspective of guiding characteristics, this is one of the main characteristics of the entire digital media. In the process of visual communication design, in order to scientifically and comprehensively understand the visual characteristics of things, they will actively seek out unconsciously. Especially, the internal connection during the reading process is more obvious. Through visual communication, we can express daily behavior habits and natural laws. Therefore, the guiding role of visual communication design is very powerful. Only with the strengthening of the strategic implementation plan can the visual results be displayed.

Second is interaction. In order to ensure the continuous improvement of visual design, both need to be considered. Traditional optical designs have relatively strong interactions and limitations. Overcoming this strong limitation, the relationship between visual design and media is getting closer [17]. In order to better improve visual design, but also to strengthen the role and effect of media in visual design. From a human point of view, humanitarianism is the driving force behind visual communication design. In other words, creating visible communication not only satisfies the spiritual needs of people but also the physical, material, and spiritual needs of people [18]. In order to enhance the value of visual communication design, the entire visual design must respect the humanitarian concept. Finally, considering the characteristics of diversification and integration, 


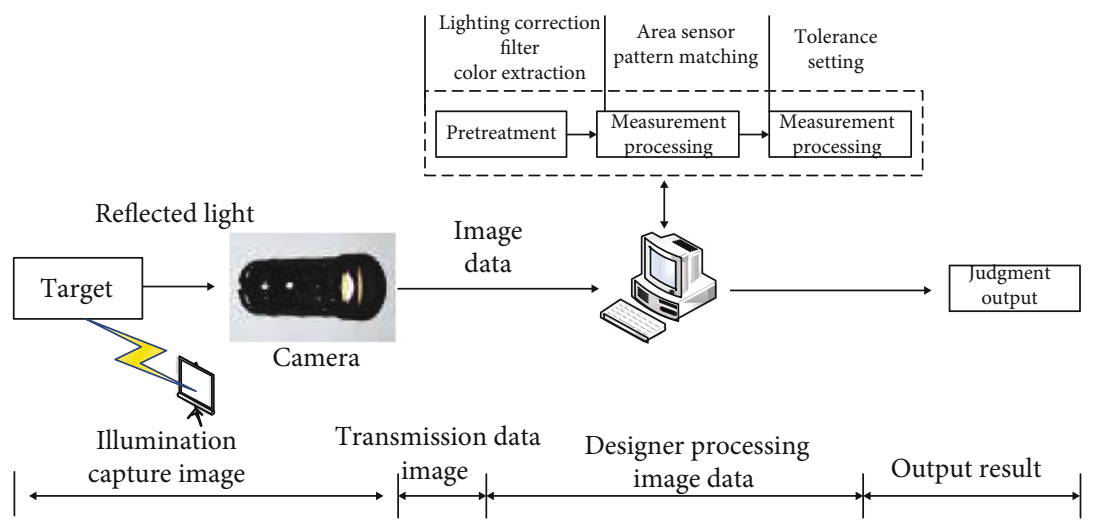

Figure 1: Visual media communication system work flow chart.

diversification is mainly the method and form for designers to obtain information. As the designer's creative visual communication design matures, it is becoming more and more popular and perfect $[19,20]$. The merger is mainly to integrate academic knowledge in visual communication design, especially to strengthen the integrity and layout of visual communication design, so that the development of actual visual communication design plans is more realistic [21].

Among all the components of visual communication design, color is the element that can most attract the viewer's visual attention. The designer uses colorful LED tubes to construct a dreamlike real space. The flashing neon lights seem to make people feel like they are in the universe and the Milky Way. They use a strong plane composition color design to beautify the entire subway space environment. Figure 2 is a visual flow chart of media communication design.

2.2. AI Technology. AI is an English standard for intelligence. Theories, systems, technologies, and systems used in research and simulation are new science; human wisdom is constantly expanding $[22,23]$. The roles of AI technology in visual media communication design are the following: (1) AI technology can provide a better presentation platform for visual media communication design, give audiences a more perfect visual enjoyment, and help designers to complete more convenient colors through AI technology matched with simulation experiments [24, 25]; (2) AI technology is conducive to showing better image perception in visual media communication design. At the same time, the use of machine vision and image recognition technology can help the concept of visual media communication design to be more comprehensive. The audience is also more able to receive information and understand the meaning [26, 27]. It can almost be said that there are transcendences in the fields of science and physics. The relationship between theory and practice is the relationship between artificial intelligence and thinking science. From a thinking point of view, artificial intelligence is not limited to reasonable thinking. To promote the innovation and development of artificial intelligence, we must study image thinking and stimulating thinking $[28,29]$.

Figure 3 shows the related applications of AI technology.

\section{Research Experiment on Color Matching and Image Application Design in AI Visual Media Communication Design}

3.1. Design Model of Color Matching and Image Application in Visual Media Communication Design Based on Genetic Algorithm in AI Technology. The application of genetic algorithms is also very large, such as human intelligence, imaging, vision, machine learning, symbol design, and other areas.

\subsubsection{The Steps and Significance of Genetic Algorithm}

(1) First select a group. In other words, select a character string or a group of $b_{i}, i=1,2, \cdots n$. The first group is a series of virtual solutions to problems. Generally speaking, $n=30-160$. Usually, it is a symbol or a group of people $b_{i}, i=1,2, \cdots n ; b_{i}$ is created randomly. The best solution to this problem is achieved by developing these first cases

(2) Select individuals as their next generation based on the principle of survival of the fittest. Here, the objective function $f$ is set, the individual is represented by $b_{i}$, and $f\left(b_{i}\right)$ is called the fitness of the individual $b_{i}$

$$
P\left\{\text { choose }_{i}\right\}=\frac{f\left(b_{i}\right)}{\sum_{j=1}^{n} f\left(b_{i}\right)} \cdot n .
$$

The number of times $b_{i}$ was selected as the next generation. Obviously, it can be seen from the above formula that the stronger the adaptability, the better the survival; the weaker the adaptability will be eliminated. This is the problem we want to solve, the optimal solution problem.

(3) The cross behavior is the random exchange of positions. It targets individuals selected for reproduction of the next generation. Crossover can be divided into single point crossover and multipoint crossover, and the crossover probability is set to $P$. The purpose of 


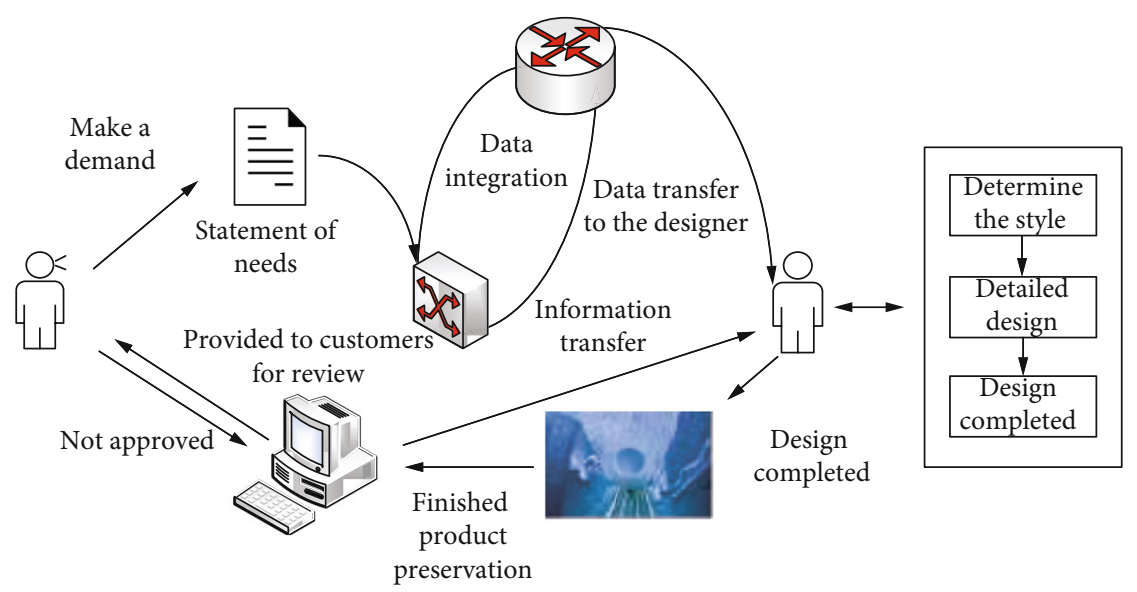

FIgURe 2: Visual flow chart of media communication design.

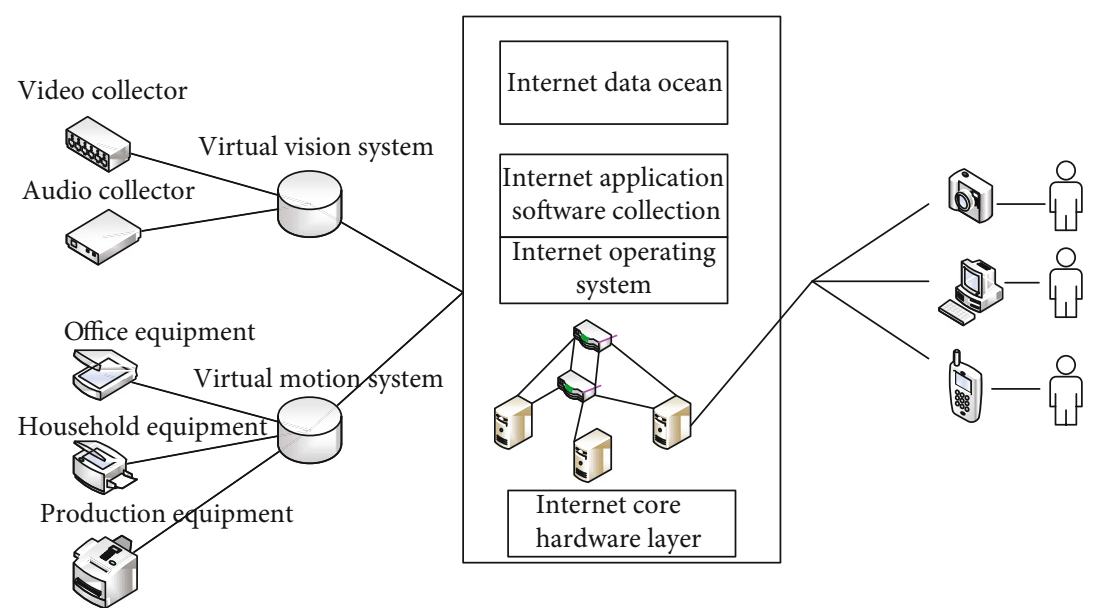

FIgURe 3: Related applications of AI technology.

crossover is to reproduce and produce new combined individuals

(4) The mutation behavior is genetic mutation. After crossover, new individuals are generated for genetic mutation. The mutation probability is $\mathrm{Pm}$, and the value range is $0.01-0.2$

(5) The global optimal convergence reaches a specific individual optimal adaptability or is no longer suitable for individual optimal adaptability. With the improvement of group adaptability, the iterative process of algorithm convergence and algorithm termination. In addition, the previous generation group has returned to the second step, which is to replace the new generation group obtained by selection, crossover, and mutation and continue the selection process

3.1.2. Application of Genetic Algorithm in Visual Media Communication Design. Genetic algorithms are well used for machine learning, image processing, etc. Image processing is a function of the communication system, i.e., the use of graphics computers. Its processing program is input images, that is, use optical character readers and other equipment to directly "read in" various graphics and tables; form images, that is, use a computer to draw a large amount of stored data into simple and clear charts; and output images, that is, the computer will output the processed image according to the style (hard copy or soft copy) that people want. Image processing helps to organize complex digital stories at length so that they are seamless and clear and fast, which is ideal for people to make better decisions. In addition to image processing, image processing also includes image compression, storage, enhancement, processing, quantization, spatial filtering, and image pattern recognition.

3.1.3. Kalman Filtering Algorithm. Kalman observation is the introduction and production of an algorithm that uses a linear state system to accurately measure the state of the system from detailed data.

First, suppose the measured value at a certain moment of the image is a fixed formula

$$
\bar{x}=\left[\begin{array}{l}
p \\
v
\end{array}\right],
$$


Table 1: Application of visual media communication design/\%.

\begin{tabular}{|c|c|c|c|c|c|c|c|}
\hline Application field & Logo design & Advertising design & Package design & Environment design & Corporate image & Orchestration & Illustration \\
\hline 2016 & 15.4 & 5.6 & 3.8 & 9.4 & 4.5 & 12.3 & 14.2 \\
\hline 2017 & 12.4 & 11.9 & 16.5 & 9.8 & 7.7 & 8.2 & 9.4 \\
\hline 2018 & 14.5 & 13.5 & 18.9 & 10.7 & 6.9 & 7.8 & 8.3 \\
\hline 2019 & 22.4 & 16.8 & 18.4 & 13.5 & 10.2 & 6.5 & 8.9 \\
\hline 2020 & 21.5 & 18.4 & 22.5 & 23.6 & 27.8 & 21.5 & 22.4 \\
\hline 2021 & 20.8 & 35.9 & 45.6 & 25.3 & 35.9 & 22.8 & 21.6 \\
\hline
\end{tabular}

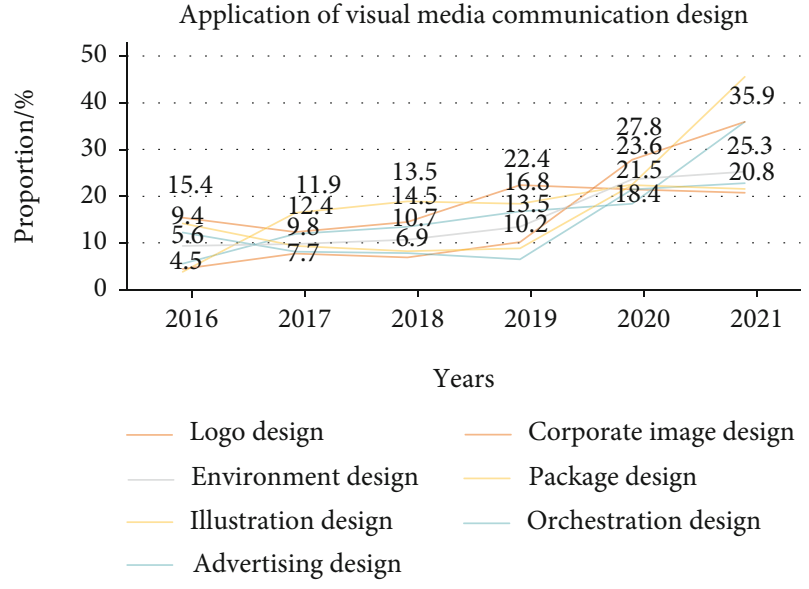

Figure 4: Application of visual media communication design/\%.

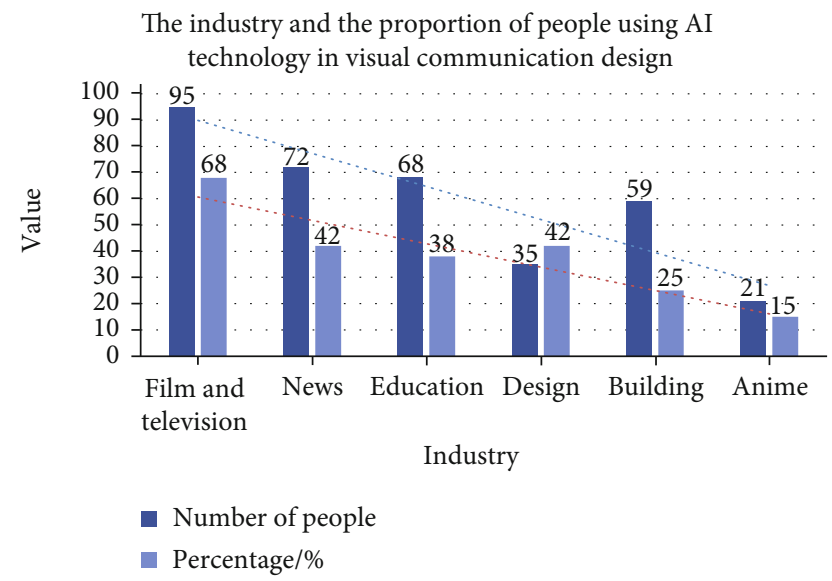

FIGURE 5: The industry and the proportion of people using AI technology in visual communication design.

then the best estimated value $\widehat{x}_{k-1}$ at the previous moment. The covariance matrix is $p_{k-1}$. Then, there is $P_{K}=P_{K-1}+\Delta$ $t v_{k-1}$ and $v_{k}=v_{k-1}$ that is

$$
\widehat{x}_{k}=\left[\begin{array}{cc}
1 & \Delta t \\
0 & 1
\end{array}\right] \widehat{x}_{k-1}=F_{k} \widehat{x}_{k-1} .
$$

At this time,

$$
p_{k}=\operatorname{cov}\left(F_{k} \widehat{x}_{k-1}\right)=F_{k} \operatorname{cov}\left(\widehat{x}_{k-1}\right) F_{k}^{T}=F_{k} P_{k-1} F_{k}^{T} .
$$

If we add an additional control amount, such as salt and pepper noise $a$, at this time $P_{k}=P_{k-1}+\Delta t v_{k-1}+(1 / 2) \Delta t^{2} a$ and $v_{k}=v_{k-1}+\Delta t a$ then at this time:

$$
\widehat{x}_{k}=F_{k} \widehat{x}_{k-1}+\left[\begin{array}{c}
\frac{\Delta t^{2}}{2} \\
\Delta t
\end{array}\right] a=F_{k} \widehat{x}_{k-1}+B_{k} \bar{u}_{k} .
$$

In addition, we must clarify that the design of our system is not $100 \%$ accurate, because there is still noise interference and $Q$ fluctuation. Therefore, we must complete the noise forecasting process as follows:

$$
\begin{gathered}
\widehat{x}_{k}=F_{k} \widehat{x}_{k-1}+B_{k} \bar{u}_{k}, \\
P_{k}=F_{k} P_{k-1} F_{k}^{T}+Q_{k} .
\end{gathered}
$$

Due to the influence of error accumulation, simple evaluation of the system will lead to more and more serious estimates, so the observation data of the sensor is used to correct the estimate. As shown in the following formula, using the same method as the prediction step, the estimated value space can be made consistent with the observed value space:

$$
\begin{gathered}
\bar{\mu}_{\text {expected }}=H_{k} \widehat{x}_{k}, \\
\sum_{\text {expected }}=H_{k} P_{k} H_{k}^{T} .
\end{gathered}
$$

Assume that the observed value is $\bar{z}_{k}$. At the same time, there are also noise interference problems such as sensor noise in the observation data, so the combination of $R_{k}$ is used to represent the distribution of this noise. Currently, the observed value $\left(\bar{Z}_{k}, R_{k}\right)$ and the estimated value ( $\left.\bar{\mu}_{\text {expected, }}, \sum_{\text {expected }}\right)$ are in the same position, but the probability distribution is different.

We multiply the Gaussian distribution of the observation value and the estimated value, and the Gaussian distribution of the result is described as follows:

$$
\begin{aligned}
& K=\sum_{0}\left(\sum_{0}+\sum_{1}\right)^{-1}, \\
& \bar{\mu}=\bar{\mu}_{0}+K\left(\bar{\mu}_{1}-\bar{\mu}_{0}\right), \\
& \sum^{\prime}=\sum_{0}\left(\sum_{0}+\sum_{1}\right)^{-1} .
\end{aligned}
$$



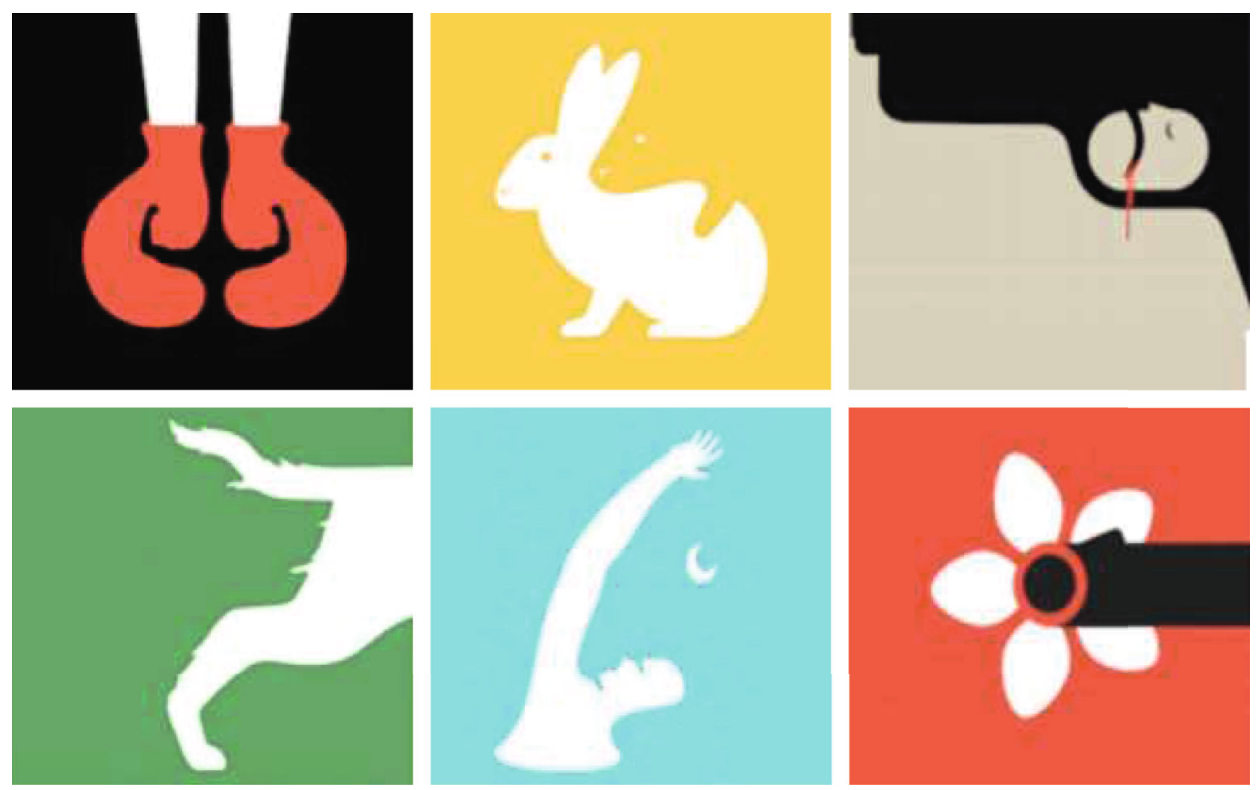

FIGURE 6: Examples of color matching and image application (picture from Baidu Gallery).

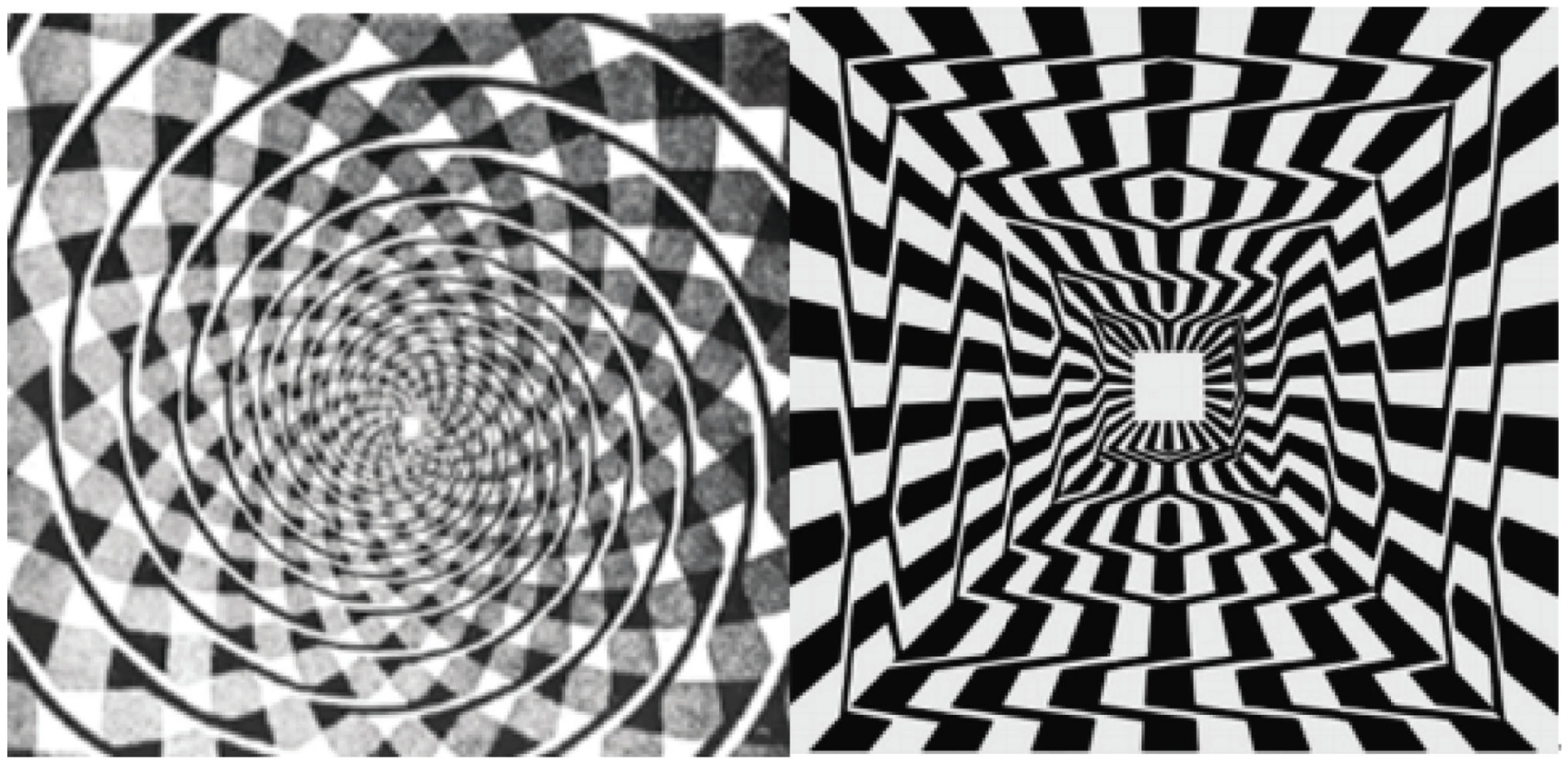

FIGURE 7: Shading circle chart and shading radiation chart (picture from Baidu Gallery).

TABLE 2: The resistance of different visual communication designs to image rotation attacks.

\begin{tabular}{lccccc}
\hline Counter clockwise rotation $2^{\circ}$ & $T=80$ & $T=160$ & $T=200$ & $T=250$ & $T=300$ \\
\hline Independent visual communication & 45.9 & 52.5 & 53.4 & 55.1 & 56.2 \\
Multimedia + visual communication & 50.2 & 62.7 & 63.6 & 68.9 & 70.1 \\
AI + visual communication & 60.3 & 83.2 & 85.9 & 84.6 & 85.6 \\
\hline
\end{tabular}




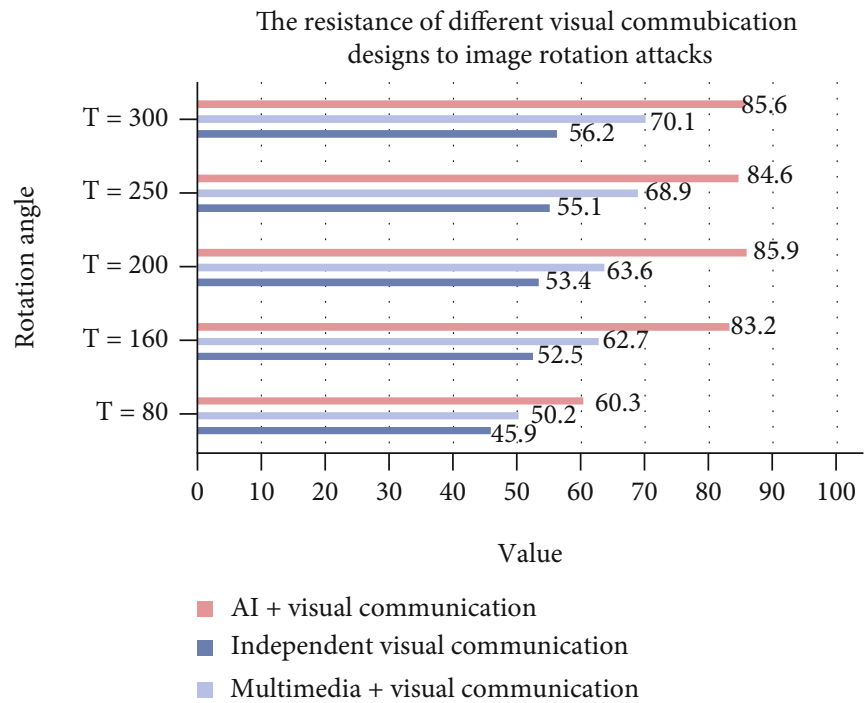

Figure 8: The resistance of different visual communication designs to image rotation attacks.

TABLE 3: Comparison of image resistance to compression.

\begin{tabular}{lccc}
\hline $\begin{array}{l}\text { Compression } \\
\text { ratio/\% }\end{array}$ & $\begin{array}{c}\text { Ordinary visual } \\
\text { communication design }\end{array}$ & $\begin{array}{c}\text { Visual communication design using } \\
\text { multimedia }\end{array}$ & $\begin{array}{c}\text { Visual media communication design using AI } \\
\text { technology }\end{array}$ \\
\hline 90 & 1.0000 & 16.6135 & 6.3130 \\
80 & 1.0000 & 12.7358 & 4.3397 \\
70 & 0.9976 & 10.2955 & 3.8235 \\
60 & 0.9976 & 9.4345 & 3.5297 \\
50 & 0.9976 & 8.2847 & 3.1483 \\
40 & 0.9976 & 7.2928 & 3.0645 \\
\hline
\end{tabular}

Then, substituting the estimated value $\left(\bar{\mu}_{0}, \sum_{0}\right)=\left(H_{k} \widehat{x}_{k}\right.$ , $\left.H_{k} P_{k} H_{k}^{T}\right)$ and the observed value $\left(\bar{\mu}_{1}, \sum_{1}\right)=\left(\bar{z}_{k}, R_{k}\right)$ into the above three formulas, you can get:

$$
\begin{aligned}
K & =H_{k} P_{k} H_{k}^{T}\left(H_{k} P_{k} H_{k}^{T}+R_{k}\right)^{-1}, \\
H_{k} \widehat{x}_{k} & =H_{k} \widehat{x}_{k}+K\left(\bar{z}_{k}-H_{k} \widehat{x}_{k}\right), \\
H_{k} P_{k} H_{k}^{T} & =H_{k} P_{k} H_{k}^{T}-K H_{k} P_{k} H_{k}^{T} .
\end{aligned}
$$

Among them, $k$ is called Kalman gain.

The cost and estimated value of the signal source is almost equal to the distribution. For a better understanding of performance, the intention is that the model will not change much. In order to obtain better results, we use the measured value of the current time node as the measured value of the $1-N$ time node. In principle, the higher the value of $N$, the better the filtering phenomenon, but the more serious the lag of the filtering result.

3.1.4. Gray Expected Image Algorithm. Let $n$ be the random size of any discrete pixel in the image $L_{1}, L_{2}, \cdots, L_{N}$. The gray distribution of image can be described by probability distribution. Suppose that the occurrence probability of each gray level is

$$
p_{1}=P\left(L_{1}\right), p_{2}=P\left(L_{2}\right), \cdots, p_{N}=P\left(L_{N}\right) .
$$

And there are

$$
\sum_{n=1}^{N} p_{n}=1
$$

This kind of random variable can be described by the following density matrix:

$$
\left[\begin{array}{c}
X \\
P(X)
\end{array}\right]=\left[\begin{array}{ccc}
L_{1} L_{2} \cdots & L_{N} \\
p_{1} p_{2} & \cdots & p_{N}
\end{array}\right] .
$$

It can be seen that for different images, the density table is different. In the mathematical model of variables, the expected value is a very important statistical record, which reflects the average value of the variables. Looking at the material used, it represents the center of mass of the object where the values of the variables are applied. Since the gray value is a random variable in the image, segmentation from the gray "center" should be the best balance point, which makes the gray value of black pixel equal to that of white pixel. Set $\mu_{\text {threshold }}$ to represent the threshold value.

$$
\mu_{\text {threshold }}=\sum_{n=1}^{N} L_{n} P\left(L_{n}\right) \text {. }
$$




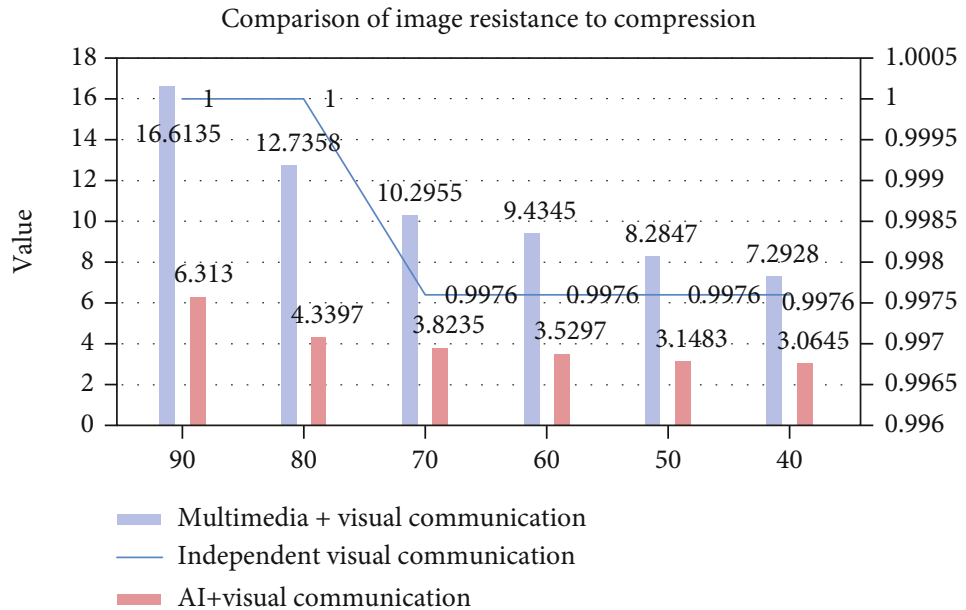

Figure 9: Comparison of image resistance to compression.

TABle 4: The purpose and medium of visual media communication design for color matching and image application.

\begin{tabular}{lcccc}
\hline Industry sector & Purpose & Percentage & Medium & Percentage \\
\hline Design industry & Convey the design concept & $78 \%$ & Paper media \\
Education industry & Achieve good teaching results & $76 \%$ & Multimedia media & Multimedia media \\
Film and television & Play ultimate viewing effect & $95 \%$ & $82 \%$ & $82 \%$ \\
Achitechive & Make a good design artwork & $57 \%$ & Paper media and multimedia media & $59 \%$ \\
News industry & Make news more colorful & $85 \%$ & Paper media & $92 \%$ \\
\hline
\end{tabular}

It can be deduced from the above formula,

$$
\begin{aligned}
\mu_{\text {threshold }} & =\sum_{n=1}^{N} L_{n} \frac{h\left(L_{n}\right)}{\sum_{m=1}^{N} h\left(L_{m}\right)}, \\
\mu_{\text {threshold }} & =\frac{\sum_{n=1}^{N} L_{n} h\left(L_{n}\right)}{\sum_{n=1}^{N} h\left(L_{n}\right)} .
\end{aligned}
$$

Its calculation process is very simple, it is very easy for hardware implementation or DSP chip, and the calculation accuracy can be fully satisfied under the condition of fixedpoint operation.

\section{Research and Analysis of Color Matching and Image Application Design in AI Visual Media Communication Design}

4.1. Status Quo of AI Visual Media Communication Design. Visual media communication design has been involved in logo design, advertising design, packaging design, internal and external environment design, corporate image design, and other industries. Between Table 1 and Figure 4, it can be seen that the proportion of visual media logo design is $20.8 \%$, advertising design is $35.9 \%$, packaging design is $45.6 \%$, interior and exterior environment design is $25.3 \%$, and corporate image design is $35.9 \%$. It can be seen from the above data that the proportion of packaging design is the highest, indicating that users are first concerned about the packaging of the product and are easily attracted by the color matching and image application of the product.

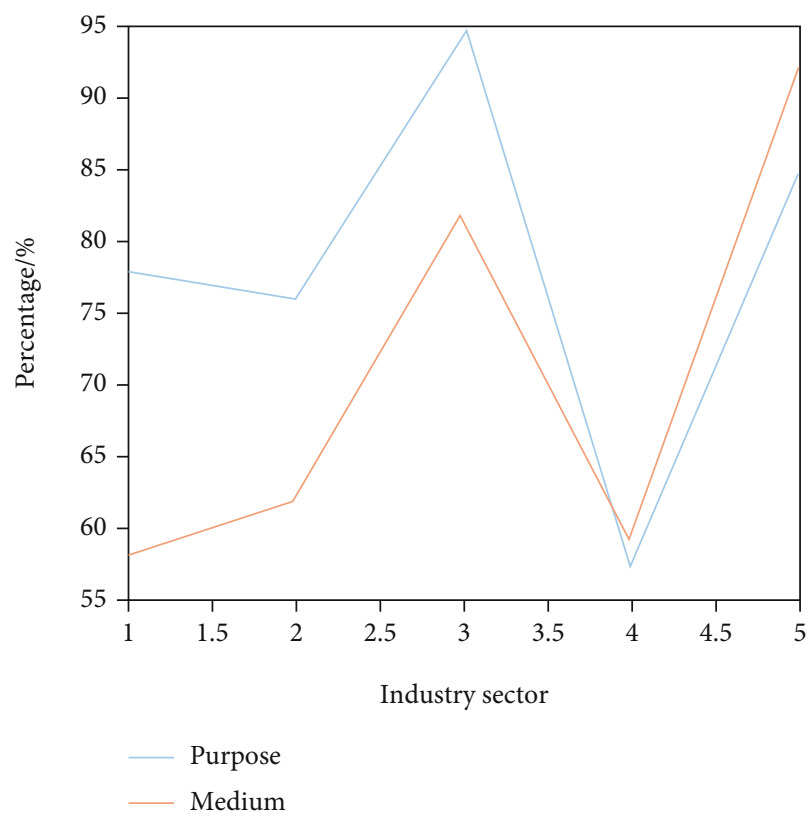

Figure 10: The purpose and medium of visual media communication design for color matching and image application.

We conducted random interviews in an art center and interviewed 380 people in the industry and the application of visual communication technology. From the survey data in Figure 5, it can be seen that among the people we interviewed, the number of people engaged in the film and television industry is the largest, with 95 people, and the 


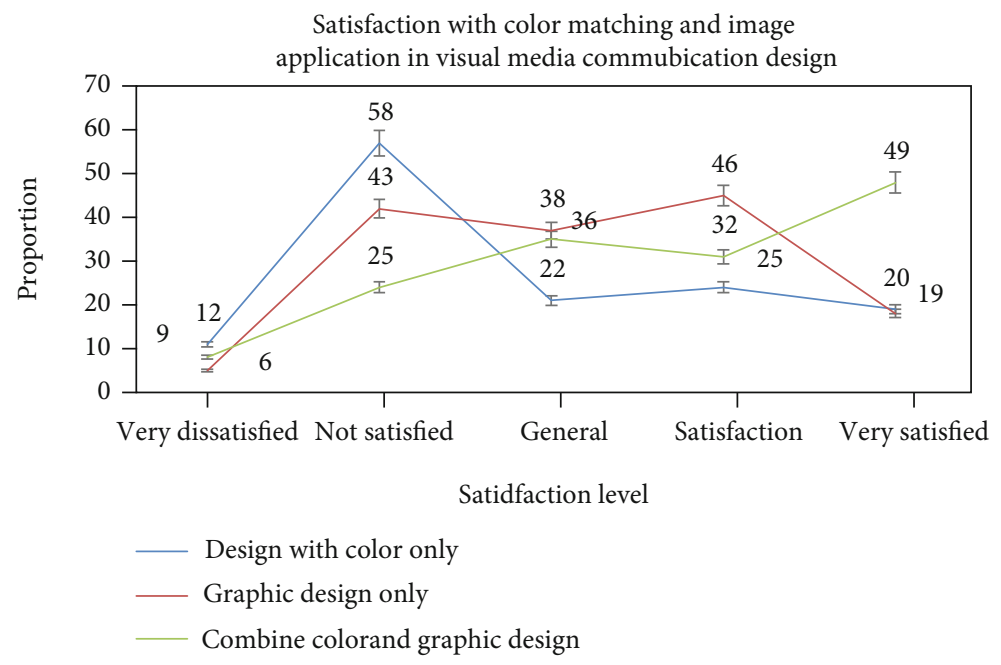

FIGURE 11: Satisfaction with color matching and image application in visual media communication design.

proportion of visual media communication design using AI technology has reached $68 \%$, followed by the news industry with 72 people accounting for $42 \%$.

4.2. Color Matching and Image Application of AI Visual Media Communication Design. Figure 6 is an example of color matching and image application. The choice and grasp of colors in visual communication design are very important. It is best for designers to use colors carefully and wisely to create an effective visual system that allows users to distinguish the similarities and differences between elements, instead of using too many colors. And the saturation of the color and the area occupied by adjacent colors must be considered. An interface that is too saturated and uses too many colors will overwhelm the user's visual senses, making it difficult to communicate effectively. The brand needs and communication needs of the interface may also conflict in color selection. Because different colors have different meanings to different cultures. Therefore, before choosing colors for the target population, you must first confirm the meaning of the selected colors and color combinations.

Figure 7 shows the same use of two colors for different images, and the visual effects are very different. The same pictures are drawn on a grid background. The curve on the left seems to be spiral, but in fact, it is concentric. Just use bamboo needles and so on to draw along the curve. The picture on the right is drawn on a radial background. The eight-layer rectangle outside the black rectangle in the center of the picture also looks skewed and not straight. Therefore, in packaging or multimedia equipment, we must pay attention to the effect of shading and color matching; otherwise, it is easy to give people a sense of dizziness and cause people's visual fatigue. Of course, if you want to temporarily use it as an eye-catching technique, it is very flattering.

It can be seen between Table 2 and Figure 8 that the robustness to rotating attack behavior is far different under different threshold $T$ selections. The selection of the threshold $T$ plays a key role in the extraction of the feature matrix.
For images with complex textures, a larger threshold value should be selected, so that the extracted features have good point stability and strong robustness to conventional signal processing.However, for flat and clear images, the threshold should be smaller to extract enough feature points to characterize the original image and avoid the problem of high watermark similarity of different images.

It can be seen between Table 3 and Figure 9 that the image application using AI technology is almost unaffected by JPEG compression, but as the compression ratio increases, the traditional visual communication design methods are affected more and more frequently. The coefficient is more sensitive than the intermediate frequency coefficient. And this contrast is more obvious, and it can be clearly seen that the image application will not change drastically as the compression ratio increases.

Between Table 4 and Figure 10, we can see that different industries use visual communication design for different purposes and media. The survey results for most people show that $78 \%$ of people believe that the design industry wants to convey design concepts and show the artistic sense of design. $76 \%$ of people in the education industry believe that visual communication designers are used for clarity and intuitiveness. Teaching, to achieve a good teaching effect, 95\% of the people in the film and television industry believe that the purpose is to achieve an ultimate viewing effect; $57 \%$ of the construction industry and $85 \%$ of the news industry also show a love for visual media communication design.

In addition, there are many kinds of media for visual media communication design. According to the characteristics of different industries, the applicable media for each industry are different. For example, in the film and television industry, multimedia media are mostly used, but in the news industry, $92 \%$ of people use paper media. This shows that with the development of technology, visual communication design has more forms of presentation, and it is also more conducive to spreading the effect of visual media communication design. 
4.3. Satisfaction Analysis of Color Matching and Image Application in Visual Media Communication Design. From the data in Figure 11, it can be seen that $58 \%$ of the people who are very dissatisfied with the visual media communication design that only use color design may be because most people do not directly understand the meaning of color; for example, red represents enthusiasm and can also represent revolution. The visual media communication design that combines color matching and image design has $49 \%$ of the people expressing satisfaction, because of the visual impact of colors and the aesthetic feeling of images.

\section{Conclusion}

This article is mainly to study the color matching and image application design in AI visual media communication design. By consulting related literature, we have deeply studied the advantages and disadvantages of traditional visual media communication design, as well as color matching methods and image application. On the basis of previous research results, this paper launches a research and analysis of color matching and image application design in AI visual media communication design.

This article first briefly describes the application of visual media communication design and AI technology and then designs a visual media communication design model based on the genetic algorithm in AI technology and removes the effect of image noise through the Kalman filter algorithm. Finally, it analyzes from three aspects, namely, the analysis of the status quo of visual media communication design, the analysis of color matching and image application in AI visual media communication design, and the satisfaction analysis of color matching and image application in visual media communication design.

The shortcomings of this article are that the application of AI technology in the design of visual media communication is not mature enough, and the related image application research is still relatively small. We need to conduct further research and explanation. In addition, the color matching and image application of visual media communication design still need to be innovated and developed.

\section{Data Availability}

The data that support the findings of this study are available from the corresponding author upon reasonable request.

\section{Conflicts of Interest}

The authors declared no potential conflicts of interest with respect to the research, authorship, and/or publication of this article.

\section{References}

[1] Y. T. Huang and Y. H. Chou, "The effects of online apparel photo code compositions to enhance women's purchase intention," International Journal of Communication and Media Studies, vol. 6, no. 3, pp. 17-26, 2016.
[2] X. Shi and Z. Zhang, "Application of visual communication design under communication theory," Agro Food Industry $\mathrm{Hi}$ Tech, vol. 28, no. 1, pp. 246-249, 2017.

[3] Z. Wan, Y. Dong, Z. Yu, H. Lv, and Z. Lv, "Semi-supervised support vector machine for digital twins based brain image fusion," Frontiers in Neuroscience, vol. 15, 2021.

[4] P. Mamoshina, L. Ojomoko, Y. Yanovich et al., "Converging blockchain and next-generation artificial intelligence technologies to decentralize and accelerate biomedical research and healthcare," Oncotarget, vol. 9, no. 5, pp. 5665-5690, 2018.

[5] S. Johnson, F. Samsel, G. Abram et al., "Artifact-based rendering: harnessing natural and traditional visual media for more expressive and engaging 3D visualizations," IEEE Transactions on Visualization and Computer Graphics, vol. 26, no. 1, pp. 492-502, 2020.

[6] X. Song, "Research on the visual communication of high quality image information in web-page design," Revista de la Facultad de Ingenieria, vol. 32, no. 14, pp. 479-484, 2017.

[7] P. Ardhianto, "Tinjauan desain pada karya poster; studi kasus seri poster "Marlyn Fish 2009"," ANDHARUPA Jurnal Desain Komunikasi Visual \& Multimedia, vol. 2, no. 1, pp. 15-22, 2018.

[8] Y. Li, J. Zhao, Z. Lv, and J. Li, "Medical image fusion method by deep learning," International Journal of Cognitive Computing in Engineering, vol. 2, pp. 21-29, 2021.

[9] N. P. B. Siti, "Perancangan buku jurnal pembelajaran 'bermain dengan serioeus' : media pembelajaran pada mata kuliah metodologi desain," ANDHARUPA Jurnal Desain Komunikasi Visual \& Multimedia, vol. 3, no. 2, pp. 115-129, 2017.

[10] Y. Erlyana and R. Ressiani, "Perancangan buku desain kemasan "basic of packaging", ANDHARUPA Jurnal Desain Komunikasi Visual \& Multimedia, vol. 6, no. 2, pp. 160-172, 2020.

[11] B. A. Hananto, "Implementasi budaya Korea pada perancangan identitas visual "Mireokki"," Jurnal Dimensi DKV Seni Rupa dan Desain, vol. 5, no. 1, pp. 1-18, 2020.

[12] E. Armayuda and R. Pragadeva, "Metode desain dari brand menjadi maskot berdasarkan adaptasi metode Alina Wheeler ke dalam model 5m," ANDHARUPA Jurnal Desain Komunikasi Visual \& Multimedia, vol. 6, no. 2, pp. 277-287, 2020.

[13] D. Chen, P. Wawrzynski, and Z. Lv, "Cyber security in smart cities: a review of deep learning-based applications and case studies," Sustainable Cities and Society, vol. 66, article 102655, 2021.

[14] A. R. Darmawan, "Papuan batik dissemination through documentary videos (case study on Phokouw Faa Batik Center)," Visualita, vol. 8, no. 1, pp. 47-52, 2019.

[15] N. Elisabeth, F. Yulika, and A. E. B. Waspada, "Desain komunikasi visual iklan layanan masyarakat tentang pelecehan seksual pada anak di kota medan," ANDHARUPA: Jurnal Desain Komunikasi Visual \& Multimedia, vol. 4, no. 2, pp. 188-195, 2018.

[16] G. Mer and S. Castellani, "Why is it important to design a visual identity for your orthodontic practice?," Revue Dorthopédie Dento Faciale, vol. 52, no. 3, pp. 305-308, 2018.

[17] N. Taylor and M. Keating, "Contemporary food imagery: food porn and other visual trends," Communication Research and Practice, vol. 4, no. 3, pp. 307-323, 2018.

[18] X. Liu, M. Dohler, and Y. Deng, "Vibrotactile quality assessment: hybrid metric design based on SNR and SSIM," IEEE Transactions on Multimedia, vol. 22, no. 4, pp. 921-933, 2020. 
[19] Z. Lv, H. Yang, A. K. Singh, G. Manogaran, and H. Lv, "Trustworthiness in industrial IoT systems based on artificial intelligence," IEEE Transactions on Industrial Informatics, vol. 17, no. 2, pp. 1496-1504, 2020.

[20] M. Haragi, H. Ishikawa, and T. Kiuchi, "Investigation of suitable illustrations in medical care," Journal of Visual Communication in Medicine, vol. 42, no. 4, pp. 1-11, 2019.

[21] P. J. B. D. Rosario, "Hermeneutic analysis of the San Isidro Pahiyas Festival as a development communication medium in Lucban, Quezon, Philippines," Journal of Hospitality and Tourism Insights, vol. 2, no. 2, pp. 203-220, 2019.

[22] H. W. Lim, Y. W. Hau, C. W. Lim, and M. A. Othman, “Artificial intelligence classification methods of atrial fibrillation with implementation technology," Computer Assisted Surgery, vol. 21, no. sup1, pp. 154-161, 2016.

[23] W. L. Chen, Y. B. Lin, F. L. Ng, C. Y. Liu, and Y. W. Lin, "RiceTalk: rice blast detection using Internet of Things and artificial intelligence technologies," IEEE Internet of Things Journal, vol. 7, no. 2, pp. 1001-1010, 2020.

[24] C. Ben, H. H. Li, T. Liu, Z. J. Wang, D. S. Cheng, and S. H. Zhu, "Advances in the research of artificial intelligence technology assisting the diagnosis of burn depth," Chinese Journal of Burns, vol. 36, no. 3, pp. 244-246, 2020.

[25] Z. Z. Li and D. Z. Yu, "Application prospect of artificial intelligence technology in vestibular disorders," Journal of Clinical Otorhinolaryngology, vol. 33, no. 9, pp. 895-897, 2019.

[26] Z. Yan and Z. Lv, "The influence of immersive virtual reality systems on online social application," Applied Sciences, vol. 10, no. 15, p. 5058, 2020.

[27] Y. Bin and D. Mandal, "English teaching practice based on artificial intelligence technology," Journal of Intelligent and Fuzzy Systems, vol. 37, no. 1, pp. 1-11, 2019.

[28] V. Machi, "Artificial intelligence top technology priority for SECDEF nominee Esper,” Defense Daily, 2019.

[29] H. Shohei, "Artificial intelligence technology for industrial robot applications," Journal of the Robotics Society of Japan, vol. 35, no. 3, pp. 186-190, 2017. 